\section{Combining Negative Pressure Wound Therapy with Insulin Instillation Reduces Insulin Resistance and Accelerates Healing in Patients with Chronically Infected Wounds}

\section{Xin-long Chen"*, Yu-yang Li", Xian-nan Liang\#, Yu-ye Wang\#, Mu-sheng Wang" and Shuai Yan ${ }^{\#}$}

Burn and Plastic Surgery Department, Sanya Central Hospital (Hainan Third People's Hospital), Sanya, Hainan Province, P. R. China

"Authors who equally contributed to this work.

\begin{abstract}
Aim: This study aimed at evaluating the effects of negative pressure wound therapy (NPWT) combined with insulin instillation on wound healing and insulin resistance (IR) in patients with chronically infected wounds.
\end{abstract}

Methods: Sixty-three patients were recruited and randomly divided into three groups (21 cases each) according to treatments: NPWT only; NPWT+insulin; and controls (conventional dressings). Both NPWT treatments lasted for three weeks. Thereafter, wounds' healing conditions were assessed. At 1 day before and 7, 14, and 21 days posttreatment Interleukin- 6 (IL-6), Interleukin- 2 (IL-2), and Tumor Necrosis Factor- $\alpha$ (TNF- $\alpha$ ) serum levels were assessed via specific double-antibody sandwich enzyme-linked immunosorbent assays; and plasma glucose and insulin were quantified via glucoseoxidase and radioimmunoassay, respectively. IR was appraised via homeostasis model assessment (HOMA-IR) and quantitative insulin sensitivity check index (QUICKI).

Results: At 7, 14, and 21 days after treatments onset the two NPWT groups had significantly $(P=0.0001)$ lower IL-6, IL-2, and TNF- $\alpha$ serum levels and HOMA-IR values than controls while wound

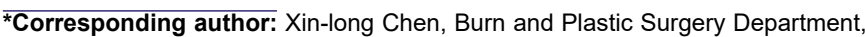
Sanya Central Hospital (Hainan Third People's Hospital), Sanya, Hainan Province, P.R. China. Tel.: +86-21-2507-0600; E-mail: cxlcxlzxy@hotmail.com

Citation: Chen X, Li Y, Liang X, Wang Y, Wang MS, et al. (2020) Combining Negative Pressure Wound Therapy with Insulin Instillation Reduces Insulin Resistance and Accelerates Healing in Patients with Chronically Infected Wounds. J Emerg Med Trauma Surg Care 7: 057

Received: May 18, 2020; Accepted: December 24, 2020; Published: December 30, 2020

Copyright: $\odot 2020$ Chen X, et al. This is an open-access article distributed under the terms of the Creative Commons Attribution License, which permits unrestricted use, distribution, and reproduction in any medium, provided the original author and source are credited. healing rates were higher $(P<0.001)$ than controls. Notably, the NPWT+insulin treatment results were better $(P<0.01)$ than those of NPWT alone.

Conclusion: NPWT+insulin instillation improved wound healing, mitigated inflammation, and reduced IR in patients with chronically infected wounds.

Keywords: Chronically infected wounds; Insulin resistance; Negative pressure wound therapy; Proinflammatory cytokines; Wound healing

\section{Abbreviations}

FBG: Fasting blood glucose

HOMA: Homeostasis Model Assessment

IL- 6: Interleukin- 6

IR: Insulin resistance

NPWT: Negative pressure wound therapy

QUICKI: Quantitative Insulin Sensitivity Check Index

TNF- $\alpha$ : Tumor Necrosis Factor- $\alpha$

\section{Introduction}

Chronically infected wounds typically result from medical conditions, nutritional deficits, infections, and metabolic disorders and require intensive and time-consuming treatments. Although recent therapeutic advances have prolonged patients' life, the incidence of difficult-to-heal wounds (i.e. sores and diabetic feet ulcers) that occur with chronic diseases has been increasing in a way commensurate with the elderly population expansion. Chronic wounds are often infected by highly virulent bacterial organisms, namely methicillin-resistant Staphylococcus aureus (MRSA) and Pseudomonas aeruginosa, that colonize biofilms and make treatments more complicated $[1,2]$. Negative-pressure wound therapy (NPWT), which prevents the accumulation of fluids through continuous drainage applied at wound sites, makes daily dressing changes unnecessary, improves regional blood flow, and by hindering bacterial proliferation curbs the chances of infection. At the cellular level, NPWT promotes collagen synthesis, neoangiogenesis, and granulation tissue formation [3-5].

Recent modifications to traditional NPWT devices allow the concurrent application of a fluid instillation therapy. The latter is designed to reduce the bioburden within the wound, advance healing, and help control pain in select cases [6-8].

Currently, only normal saline is used for the instillation therapy coupled to NPWT. Solutions of insulin, phenytoin (Dilantin), sodium hypochlorite (Dakin's solution), and polyhexanide (Prontosan, Braun Medical) have also been proposed as therapeutically useful. Several studies have demonstrated that insulin promotes wound healing [913]. Notably, Lopez and Mena [14] used local insulin irrigation (30-60 IU isophane insulin daily) in two cases of diabetic infectious gangrene that were unaffected by all the other previous therapies. They found that the insulin accelerated wound healing with no systemic side effects. 
Citation: Chen X, Li Y, Liang X, Wang Y, Wang MS, et al. (2020) Combining Negative Pressure Wound Therapy with Insulin Instillation Reduces Insulin Resistance and Accelerates Healing in Patients with Chronically Infected Wounds. J Emerg Med Trauma Surg Care 7: 057.

In the present study, we investigated the effects of NPWT combined with insulin instillation on insulin resistance (IR) and wound healing rates in patients suffering from chronically infected wounds.

\section{Materials and Methods}

\section{Patients inclusion criteria}

The following recruitment criteria were adopted: $(i)$ patients with chronically infected wounds for over one month caused by all kinds of traumata or with continuously deteriorating wounds or with wounds having diameters larger than $5 \mathrm{~cm}$; (ii) patients not previously treated with NPWT; (iii) patients showing no improvement after 7 days of standard drug therapy for a wound; and (iv) patients with infected wounds.

\section{Patients exclusion criteria}

The ensuing ruling out criteria were chosen: $(i)$ patients with combined severe heart, brain, liver, kidney, or hematopoietic diseases; (ii) patients with malignant tumors originated in skin or soft tissues; (iii) patients with immunological diseases who had been exposed for extended periods of time to high doses of immunosuppressive agents, steroid hormones, or chemotherapy drugs; (iv) and patients with severe malnutrition or moderate to severe anemia.

\section{Medical ethics}

The Medical Ethics Committee of the Third People's Hospital of Hainan Province reviewed and approved the present study. Patients or their next-of-kin signed the informed consents.

\section{Patients studied}

In this study, a total of 33 males and 30 females with chronically infected wounds admitted to the Third People's Hospital of Hainan Province from January 2015 to December 2018 were enrolled. Their age ranged from 46 to 68 years, with a mean value of $57.5 \pm 9.4$ years. Regarding wounds causes, 17 cases presented burn injuries; 9 cases had car accident injuries; 19 cases suffered from diabetic foot ulcers; and 18 cases had pressure ulcers. Concerning wounds locations, they were at the trunk (15 cases), the arms ( 9 cases), the legs ( 24 cases), and the hips ( 15 cases) (Table 1$)$.

\begin{tabular}{|l|c|c|c|}
\hline & Controls & NPWT alone & NPWT+insulin \\
\hline Male/female & $11 / 10$ & $10 / 11$ & $12 / 9$ \\
\hline Age (years) & $56.8 \pm 9.6$ & $59.3 \pm 8.3$ & $57.6 \pm 9.1$ \\
\hline Wound causes & & & \\
\hline Burn injury & 6 & 5 & 6 \\
\hline Car accident & 4 & 3 & 2 \\
\hline Diabetic foot & 6 & 7 & 6 \\
\hline Pressure ulcers & 5 & 6 & 7 \\
\hline Wound locations & & & 6 \\
\hline Trunk & 5 & 4 & 3 \\
\hline Arms & 3 & 3 & 7 \\
\hline Legs & 8 & 9 & 5 \\
\hline Hips & 5 & 5 & $49.3 \pm 8.9$ \\
\hline Wound areas $\left(\mathrm{cm}^{2}\right)$ & $48.6 \pm 9.3$ & $50.1 \pm 10.6$ & \\
\hline \multicolumn{4}{|c|}{ Table 1: Geral data of the enrolled patients. } \\
\hline
\end{tabular}

Data are means \pm SD. No statistically significant difference among the three groups. Each group's $n=21$.
The 63 patients were randomly divided into three groups (21 patients/group) ccording to the treatment:

- control group (conventional dressings);

- NPWT only group; and

- NPWT+insulin instillation group.

Three groups underwent operative debridement under general anesthesia with intubation. Anesthesia was induced by infusing sevoflurane+TCI (target-controlled infusion), propofol $\left(1 \mathrm{pg} \cdot \mathrm{mL}^{-1}\right)$ and kept with sevoflurane+TCI propofol $\left(1 \mathrm{pg} \cdot \mathrm{mL}^{-1}\right)$. Next the patients were intubated for mechanical ventilation. After successfully inducing anesthesia, all wounds were rinsed thrice with benzalkonium bromide, povidone iodine, and $0.5 \%$ iodophor solution. This was followed by saline rinses to clean the wounds and surrounding areas and to remove the necrotic stratum corneum. The shapes and sizes of the wounds conditioned the specific application of the NPWT dressings (Shandong Chuangkang Biotechnology Co., Ltd.).

If the wound area was extended, the NPWT dressing was applied in an imbricate mode completely covering the wound and $2-3 \mathrm{~cm}$ of the contouring skin. If the wound was deep, the dressings filled the cavities to the bottom, leaving no dead spaces. A biologically permeable film applied above the dressing covered an area by $4-5 \mathrm{~cm}$ wider than the wound surface. After doubly checking the sealing tightness, the drainage tube was connected to a negative pressure drainage device (Shandong Weigao New Life Medical Devices Co., Ltd., Weihai, China). Next, a negative pressure of $80-125 \mathrm{mmHg}$ was applied and maintained. Wounds dressings were replaced every 5 days. During the drainage period, the wounds of the two NPWT groups were rinsed daily with copious amounts of saline. In the NPWT+insulin treated group, the used NPWT devices allowed for insulin infusion according to the dosing defined by Wilson and associates [15]. NPWT was initiated soon after debridement on post-operation day and lasted for a period of three weeks. The intermittent streaming of insulin infusion through the NPWT device and the insulin infusion drip into the NPWT foam at $1000 \mathrm{ml} / 100 \mathrm{U} / 24 \mathrm{~h}$ continued for 3 weeks (Figures 1 and 2 ). Thereafter, the healing situation was assessed. The wounds were photographed and independently measured using ImageJ software to calculate their areas [16].

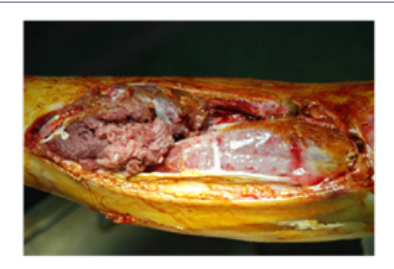

(A) Intraoperative debridement

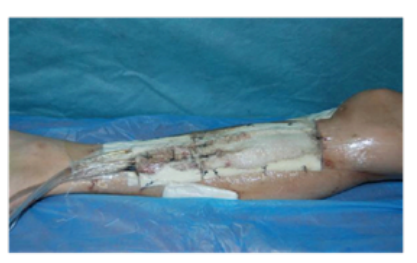

(B) Application of NPWT
Figure 1: Infected wound at the right lower leg.

The $\%$ wound healing rate was calculated according to the formula: $\%$ wound healing rate $=$ (initial wound area - residual wound area $) /$ initial wound area $\times 100$.

\section{Assay of proinflammatory factors}

Upper limb venous blood (5 ml) was sampled in the morning after an overnight fast at 1 day before and 7, 14, and 21 days after treatments onset. The serum levels of Interleukin (IL)-6, IL-2, and Tumor Necrosis Factor (TNF)- $\alpha$ were measured using specific doubleantibody sandwich enzyme-linked immunosorbent assays. The kits were from Shanghai Beyotime Biotechnology Inc. (Shanghai, China). 


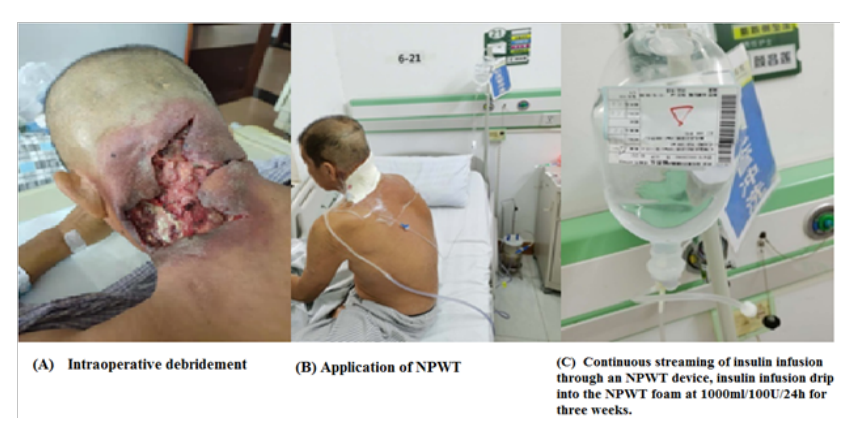

Figure 2: Infected wounds at the head and neck.

\section{Measurement of biochemical parameters}

While the hyper insulinemic euglycemic clamp technique is the gold standard for gauging insulin sensitivity, HOMA for IR (HOMAIR) and QUICKI are widely used according to the method described by Matthews et al [17-20] as noninvasive surrogate markers of IR and insulin sensitivity, respectively.

At baseline, in the morning after an overnight fast, venous blood was sampled to quantify the plasma concentration of glucose via a glucose-oxidase method and serum insulin levels via radioimmunoassay. HOMA-IR values were calculated according to the formula:

$$
\text { HOMA-IR }=(\text { Insulin } \times \text { FBG }) / 22.5 .
$$

FBG, fasting blood glucose. Low HOMA-IR values indicate a high insulin sensitivity, whereas high HOMA-IR values indicate a low insulin sensitivity. The QUICKI values were calculated according to the formula:

QUICKI $=1 /[\log ($ fasting insulin $)+\log ($ fasting glucose $)][18]$.

\section{Statistical analysis}

Data were processed and analyzed using SPSS 20.0 statistical software (IBM SPSS, Armonk, NY, USA). Numerical data were expressed as mean values $\pm \mathrm{SD}$. Before and after the treatments intergroup comparisons were carried out by $t$-test, whereas a paired $t$-test was used for intra-group comparisons.

\section{Results}

\section{General data of patients}

Age, sex ratios, and wound areas did not significantly $(p>0.05)$ differ among the three groups of patients (Table 1). There were statistically not significant $(\mathrm{P}>0.05)$ differences of wound types or wound sites among the various groups.

Six, six, and seven cases out of 19 patients suffered from diabetic foot ulcers and were randomly entered in the: (i) control group (conventional dressings); (ii) NPWT only group; and (iii) NPWT+insulin instillation group. No patient withdrew from the study during the entire treatment duration.

\section{Levels of proinflammatory factors}

The pre-treatment differences in serum levels of three proinflammatory mediators, i.e. IL- 6 , IL-2, and TNF- $\alpha$, were not statistically significant $(\mathrm{P}=0.498,0.799$, and 0.798 , respectively) in the three groups of patients. At 7, 14, and 21 days after treatments onset, the serum levels of the same proinflammatory mediators were significantly lower in the NPWT+insulin and NPWT alone groups ( $\mathrm{P}<0.01$, and 0.001 , respectively) $v s$. the control group. At the same time-points, in the three groups of patients the levels of the three proinflammatory mediators were significantly lower $(\mathrm{P}<0.01$, and 0.001 , respectively) than 1 day before treatments start (Tables $2,3,4$ ).

\begin{tabular}{|c|c|c|c|c|}
\hline & Controls & NPWT alone & NPWT+insulin & $\mathrm{p}$ \\
\hline 1 day before treatment & $35.5 \pm 2.5$ & $36.6 \pm 3.0$ & $36.2 \pm 4.2$ & 0.498 \\
\hline 7 day after treatment & $26.8 \pm 1.5$ & $14.8 \pm 2.6$ & $14.1 \pm 2.6$ & 0.0001 \\
\hline 14 day after treatment & $24.3 \pm 3.1$ & $12.1 \pm 1.9$ & $7.2 \pm 1.6$ & 0.0001 \\
\hline 21 day after treatment & $20.2 \pm 2.9$ & $8.6 \pm 1.1$ & $5.3 \pm 2.1$ & 0.0001 \\
\hline Data are means \pm SD. Each group's $\mathrm{n}=21$.
\end{tabular}

Table 2: Serum levels (ng/ml) of IL-6 before and after treatments.

\begin{tabular}{|c|c|c|c|c|}
\hline & Controls & NPWT alone & NPWT+insulin & $\boldsymbol{p}$ \\
\hline 1 day before treatment & $132.3 \pm 12.3$ & $131.6 \pm 11.5$ & $129.9 \pm 11.9$ & 0.799 \\
\hline 7 day after treatment & $108.6 \pm 8.9$ & $58.3 \pm 6.9$ & $50.3 \pm 6.2$ & 0.001 \\
\hline 14 day after treatment & $96.5 \pm 7.6$ & $50.2 \pm 8.3$ & $34.3 \pm 3.1$ & 0.0001 \\
\hline 21 day after treatment & $88.6 \pm 6.8$ & $41.6 \pm 7.2$ & $20.6 \pm 4.1$ & 0.0001 \\
\hline \multicolumn{5}{|c|}{ Data are means \pm SD. Each group's $\mathrm{n}=21}$. \\
\hline
\end{tabular}

Table 3: Serum levels (ng/ml) of IL-2 before and after treatments.

\begin{tabular}{|c|c|c|c|c|}
\hline & Controls & NPWT alone & NPWT+insulin & $P$ \\
\hline 1 day before treatment & $109.4 \pm 10.5$ & $115.5 \pm 12.3$ & $113.6 \pm 11.6$ & 0.798 \\
\hline 7 day after treatment & $87.3 \pm 12.8$ & $64.6 \pm 10.3$ & $58.3 \pm 9.1$ & 0.001 \\
\hline 14 day after treatment & $65.3 \pm 11.8$ & $35.2 \pm 6.8$ & $20.3 \pm 3.2$ & 0.0001 \\
\hline 21 day after treatment & $59.9 \pm 6.4$ & $29.6 \pm 4.2$ & $15.5 \pm 3.6$ & 0.0001 \\
\hline \multicolumn{5}{|c}{ Data are means \pm SD. Each group's $\mathrm{n}=21}$.
\end{tabular}

Table 4: Serum levels (ng/ml) of TNF- $\alpha$ before and after treatments.

\section{Residual wound areas and wound healing rates}

The residual wound areas and wound healing rates were compared among the three groups patients at 7,14 , and 21 days after treatments onset. The mean residual wound area was smallest, and the healing rates were highest in the NPWT + insulin group $(\mathrm{P}<0.01 v s$. controls in both instances).

The NPWT alone group also had better results $(\mathrm{P}<0.01)$ than the controls (Tables 5, 6, 7).

\begin{tabular}{|c|c|c|c|c|}
\hline & Controls & NPWT alone & NPWT+insulin & $P$ \\
\hline Residual wound area $\left(\mathrm{cm}^{2}\right)$ & $35.3 \pm 5.4$ & $28.6 \pm 2.9$ & $25.6 \pm 2.1$ & 0.01 \\
\hline Wound healing rate $(\%)$ & $27.4 \pm 4.7$ & $42.9 \pm 3.4$ & $48.1 \pm 2.6$ & 0.01 \\
\hline \multicolumn{6}{|c|}{ Data are means \pm SD. Each group's $\mathrm{n}=21}$. \\
\hline
\end{tabular}

Table 5: Wound healing in the three groups at 7 days of treatment. 
Citation: Chen X, Li Y, Liang X, Wang Y, Wang MS, et al. (2020) Combining Negative Pressure Wound Therapy with Insulin Instillation Reduces Insulin Resistance and Accelerates Healing in Patients with Chronically Infected Wounds. J Emerg Med Trauma Surg Care 7: 057.

\begin{tabular}{|c|c|c|c|c|}
\hline & Controls & NPWT alone & NPWT+insulin & $P$ \\
\hline Residual wound area $\left(\mathrm{cm}^{2}\right)$ & $30.3 \pm 4.6$ & $18.9 \pm 2.6$ & $13.3 \pm 1.9$ & 0.001 \\
\hline Wound healing rate (\%) & $37.0 \pm 4.7$ & $62.2 \pm 3.6$ & $73.0 \pm 3.9$ & 0.001 \\
\hline \multicolumn{6}{|c|}{ Data are means \pm SD. Each group's $\mathrm{n}=21}$. \\
\hline
\end{tabular}

Table 6: Wound healing in the three groups at 14 days of treatment.

\begin{tabular}{|c|c|c|c|c|}
\hline & Controls & NPWT alone & NPWT+insulin & $\boldsymbol{P}$ \\
\hline Residual wound area $\left(\mathrm{cm}^{2}\right)$ & $28.1 \pm 2.9$ & $15.6 \pm 1.9$ & $8.9 \pm 1.3$ & 0.01 \\
\hline Wound healing rate (\%) & $42.2 \pm 3.9$ & $68.9 \pm 3.4$ & $81.9 \pm 3.1$ & 0.01 \\
\hline \multicolumn{4}{|c|}{ Data are means \pm SD. Each group's $\mathrm{n}=21}$. \\
\end{tabular}

Table 7: Wound healing in the three groups at 21 days of treatment.

\section{Fasting blood glucose, insulin, HOMA-IR, and QUICKI}

The values of fasting plasma glucose, insulin levels, HOMAIR, and QUICKI did not significantly differ $(\mathrm{P}=0.58,0.38,0.42$, and 0.52 , respectively) among the three groups at 1 day before the treatments start. At 7, 14, and 21 days after treatments onset, both the NPWT alone and NPWT+insulin groups had significantly lower $(\mathrm{P}<$ $0.01,0.001$, and 0.001 , respectively) fasting serum insulin levels than the control group (Tables 8, 9, 10, 11).

\begin{tabular}{|c|c|c|c|c|}
\hline & Controls & NPWT alone & NPWT+insulin & $\boldsymbol{p}$ \\
\hline FBG $(\mathrm{mmol} / \mathrm{l})$ & $10.7 \pm 0.6$ & $11.3 \pm 0.8$ & $11.1 \pm 0.9$ & 0.58 \\
\hline Insulin $(\mathrm{pmol} / \mathrm{l})$ & $123.6 \pm 13.6$ & $128.9 \pm 12.6$ & $121.7 \pm 13.4$ & 0.38 \\
\hline HOMA-IR & $58.8 \pm 6.7$ & $64.7 \pm 5.6$ & $60.1 \pm 6.2$ & 0.42 \\
\hline QUICKI & $0.32(0.25,0.41)$ & $0.32(0.23,0.45)$ & $0.32(0.28,0.39)$ & 0.52 \\
\hline
\end{tabular}

Except where otherwise indicated, values are means $(95 \%$ confidence interval $) \pm \mathrm{SD}$. FBG, fasting blood glucose. QUICKI, Quantitative Insulin Sensitivity Check Index $=1$ / $[\log ($ Insulin $)+\log (\mathrm{FBG})]$.

HOMA for insulin resistance $($ HOMA-IR $)=($ Insulin $\times$ FBG $) / 22.5$. Each group's $n=21$.

Table 8: Fasting blood glucose, insulin, HOMA-IR, and QUICKI at 1 day before treatment.

\begin{tabular}{|c|c|c|c|c|}
\hline & Controls & NPWT alone & NPWT+insulin & $\boldsymbol{p}$ \\
\hline FBG (mmol/l) & $9.9 \pm 0.7$ & $10.1 \pm 0.6$ & $9.8 \pm 0.8$ & 0.37 \\
\hline Insulin (pmol/1) & $118.6 \pm 4.5$ & $61.7 \pm 2.9$ & $59.6 \pm 2.4$ & 0.01 \\
\hline HOMA-IR & $52.2 \pm 4.5$ & $27.7 \pm 3.1$ & $25.9 \pm 3.8$ & 0.001 \\
\hline QUICKI & $0.33(0.29,0.36)$ & $0.36(0.31,0.53)$ & $0.36(0.28,0.45)$ & 0.001 \\
\hline
\end{tabular}

Except where otherwise indicated, values are means $(95 \%$ confidence interval $) \pm \mathrm{SD}$ FBG, fasting blood glucose. QUICKI, Quantitative Insulin Sensitivity Check Index $=1$ / $[\log ($ Insulin $)+\log (\mathrm{FBG})]$.

HOMA for insulin resistance $($ HOMA-IR $)=($ Insulin $\times$ FBG $) / 22.5$. Each group's $n=21$.

Table 9: Fasting blood glucose, insulin, HOMA-IR, and QUICKI at 7 days of treatment.

In the two NPWT groups, significant $(\mathrm{P}<0.001,0.001$, and 0.001 , respectively) decreases in HOMA-IR values, and as well significant ( $\mathrm{P}<0.001,0.001$, and 0.001 , respectively) increases in QUICKI values occurred at 7,14 , and 21 days of treatment.

\begin{tabular}{|c|c|c|c|c|}
\hline & Controls & NPWT alone & NPWT+insulin & $\boldsymbol{p}$ \\
\hline FBG (mmol/1) & $9.8 \pm 0.5$ & $9.6 \pm 0.6$ & $9.4 \pm 0.7$ & 0.374 \\
\hline Insulin (pmol/1) & $111.8 \pm 2.6$ & $38.6 \pm 2.9$ & $22.2 \pm 3.1$ & 0.001 \\
\hline HOMA-IR & $48.7 \pm 5.2$ & $16.5 \pm 2.3$ & $9.3 \pm 1.8$ & 0.001 \\
\hline QUICKI & $0.33(0.27,0.45)$ & $0.39(0.36,0.53)$ & $0.43(0.38,0.60)$ & 0.001 \\
\hline
\end{tabular}

Except where otherwise indicated, values are means $(95 \%$ confidence interval $) \pm \mathrm{SD}$. FBG, fasting blood glucose. QUICKI, Quantitative Insulin Sensitivity Check Index $=1$ / $[\log ($ Insulin $)+\log (\mathrm{FBG})]$. HOMA for insulin resistance $($ HOMA-IR $)=($ Insulin $\times$ FBG $)$ /22.5. Each group's $n=21$.

Table 10: Fasting blood glucose, insulin, HOMA-IR, and QUICKI at 14 days of treatment.

\begin{tabular}{|c|c|c|c|c|}
\hline & Controls & NPWT alone & NPWT+insulin & $\boldsymbol{p}$ \\
\hline FBG $(\mathrm{mmol} / \mathrm{l})$ & $9.5 \pm 1.4$ & $9.2 \pm 0.9$ & $9.3 \pm 0.6$ & 0.588 \\
\hline Insulin $(\mathrm{pmol} / \mathrm{l})$ & $108.3 \pm 9.4$ & $26.6 \pm 2.8$ & $8.4 \pm 2.1$ & 0.001 \\
\hline HOMA-IR & $45.7 \pm 5.2$ & $10.9 \pm 2.3$ & $3.5 \pm 0.6$ & 0.001 \\
\hline QUICKI & $0.33(0.27,0.45)$ & $0.42(0.36,0.54)$ & $0.53(0.40,0.69)$ & 0.001 \\
\hline
\end{tabular}

Except where otherwise indicated, values are means $(95 \%$ confidence interval $) \pm \mathrm{SD}$. FBG, fasting blood glucose. QUICKI, Quantitative Insulin Sensitivity Check Index $=1$ / $[\log ($ Insulin $)+\log ($ FBG $)]$. HOMA for insulin resistance $($ HOMA-IR $)=($ Insulin $\times$ FBG $)$ 22.5. Each group's $n=21$

Table 11: Fasting blood glucose, insulin, HOMA-IR, and QUICKI at 21day of treatment.

Notably, already after one week the NPWT brought about significant $(\mathrm{P}<0.001$, and 0.001 , respectively) improvements in insulin sensitivity vs. controls as shown by the reductions in HOMAIR and increases in QUICKI values (Table 9).

Therefore, our findings show that NPWT improves insulin sensitivity in patients with chronically infected wounds. They also suggest that the metabolic effects of the NPWT may be more pronounced in such patients.

\section{Discussion}

Chronically infected wounds are quite commonly encountered in clinical settings. These wounds do not heal for extended periods, and their conventional treatment consists mainly in dressing changes. Chronic wound healing takes a long time, and if the wound does not heal at all, eventually a repairing skin graft must be surgically applied. Chronic ulcer wounds often associate with chronic infections that resist to multiple antibiotics, thus resulting in shortened survival rates of the repairing skin grafts and posing serious challenges to clinical treatment $[21,22]$.

Several studies [23-26] have shown that NPWT can effectively shorten wound healing times, lessen the pain associated with dressing changes, and effectively prevent cross-infections. NPWT is performed in a closed system, and the negative pressure drainage promptly removes any local exudate and necrotic tissue thus achieving zero necrotic tissue accumulation. In addition, NPWT protects the wound from contaminations, stimulates a fast and healthy growth of the granulation tissue, promotes healing, curbs antibiotics use, and increases blood flow close to the wound surface. The continuous negative pressure can be adjusted to match physiological conditions so that it does not adversely affect blood circulation. Moreover, it 
can effectively prevent the formation of residual abscesses and of dead spaces [27]. More importantly, the negative pressure promotes a continuous flow of body fluids from the wound surface to the drainage tube, which provides an effective and sustained auxiliary push to blood circulation [26].

Insulin can be applied topically with minimal systemic side effects while successfully decreasing the time required for wound healing. In experimental diabetic wound models, insulin significantly increased the healing rate by mitigating the inflammatory response and rescuing cell functions [12]. Topical insulin applications after injuries rapidly upregulate insulin signaling-related proteins in the wounded areas [13]. Lines of evidence also show that systemic insulin administration to diabetic mice leads to an increased prevalence of biofilms in the wound areas [28]. Topical application of insulin may be a promising therapeutic approach because it activates insulin signaling and accelerates wound healing without any of the noxious effects that sometimes associate with its systemic administration. Scimeca et al. [29] reported the use of insulin as a chemotherapeutic agent in continuous-instillation NPWT. In fact, NPWT coupled with a continuous streaming of insulin may provide a promising approach to promote a healthy wound environment. Preliminary reports seem to suggest that topically applied insulin evokes minimal systemic side effects while successfully decreasing the wound healing time. In our study, we found that the continuous streaming of insulin infusion through the NPWT device improved wound healing, mitigated inflammation, and reduced IR in patients with chronically infected wounds. To our knowledge, this is the first report in the Literature that local insulin infusion reduces IR in patients with chronically infected wounds.

In this study, we found that combined NPWT+insulin instillation was beneficial already after the first week of treatment, and quickly reduced the wound-related symptoms. In addition, NPWT+insulin increased the wound-healing rate. These findings show that the growth-promoting effects of insulin on the epidermal cells is enhanced under the NPWT's continuous negative pressure because of the blood circulation boost and the inflammatory response mitigation.

Patients with chronically infected refractory wounds experience strong local inflammatory responses as proved by the elevated circulating levels of proinflammatory mediators such as IL-6, IL2 , and TNF- $\alpha$ [30]. Nasole et al. [30] reported that IL-6 and TNF- $\alpha$ are general inflammation crucial pivots, which both directly and indirectly induce the production of other cytokines and growth factors affecting the functions of the endothelial cells and fibroblasts. The proinflammatory cytokine TNF- $\alpha$ is a central regulator of IR [31]. Proinflammatory IL-6, a biomarker of obesity and type 2 diabetes mellitus (T2DM) [32], is also a critical contributor to IR [ 33, 34].

With the healing of wounds, local inflammation rapidly vanes, and the levels of inflammatory factors go back to normal, resulting in a decreased decay of wound tissue proteins and in the promotion of wound healing. In this study, the NPWT+insulin treatment proved to be more effective than standard dressings in lowering the levels of proinflammatory factors.

IR is the lost ability of metabolic tissues like liver, skeletal muscle, skin, and adipose tissue to respond to insulin [35]. IR has long been considered as a major hallmark of the etiology and pathogenesis T2DM. IR development is mainly associated with low-grade tissue- specific inflammatory responses induced by various proinflammatory and/or oxidative stress mediators, particularly cytokines such as IL$1 \beta$, IL-6, and TNF- $\alpha$, numerous chemokines, and adipokines [3638]. Chronic exposure to proinflammatory mediators stimulates the activation of cytokine signaling-related proteins, which ultimately block the activation of insulin receptors' signaling in the $\beta$-cells of pancreatic islets [36].

In the clinical settings, IR results from a combination of factors such as an altered function of insulin-targeted cells, the noxious effects of circulating insulin antagonists, and the local accumulation of macrophages that secrete proinflammatory mediators [39]. At the molecular level, the pathological progression of IR is crucially favored by a reduced expression of insulin receptors on the part of the target cells along with an impaired insulin dependent PI3K activation and downstream signaling [40]. Over one hundred known pathologic factors contribute to deficits in wound healing [41]. A relevant one of these factors might be the disruption of insulin's signaling pathways, which is the most distinctive pathological change in T2DM [42]. In addition to the effect on glucose disposal, insulin stimulates DNA synthesis and cell proliferation. Insulin's dysfunction often associates with proliferative abnormalities at the skin (e.g. acanthosis nigricans), ovary, and heart level [43].

In this study of patients with chronically infected wounds, a significant $(\mathrm{p}<0.05)$ fall in serum insulin levels occurred already after one week of NPWT treatment, as manifested by the significant improvements in both HOMA-IR and QUICKI values when compared with control ones. These changes for the better persisted at 14 and 21 days of treatment. Notably, under these respects NPWT+insulin was more beneficial than NPWT used alone.

In conclusion, the combined NPWT+insulin treatment mitigates the inflammatory response, lessens IR, and improves wound healing in patients with chronically infected wounds.

\section{References}

1. Arias CA, Murray BE (2009) Antibiotic-resistant bugs in the 21st century: a clinical super-challenge. N Engl J Med 360: 439-443.

2. Merckoll P, Jonassen TO, Vad ME, Jeansson SL, Melby KK (2009) Bacteria, biofilm, and honey: a study of the effects of honey on 'planktonic' and biofilm-embedded chronic wound bacteria. Scand J Infect Dis 41: 341347.

3. De Laat EH, van den Boogaard $\mathrm{MH}$, Spauwen $\mathrm{PH}$, van Kuppevelt $\mathrm{DH}$, van Goor H, et al. (2011) Faster wound healing with topical negative pressure therapy in difficult-to-heal wounds: a prospective randomized controlled trial. Ann Plast Surg 67: 626-631.

4. Kim BS, Choi WJ, Baek MK, Kim YS, Lee JW (2011) Limb salvage in severe diabetic foot infection. Foot Ankle Int. 32: 31-37.

5. Scherer SS, Pietramaggiori G, Mathews JC, Prsa MJ, Huang S, et al. (2008) The mechanism of action of the vacuum-assisted closure device. Plast Reconstr Surg 122: 786-797.

6. Wolvos T (2004) Wound instillation--the next step in negative pressure wound therapy. Lessons learned from initial experiences. Ostomy Wound Manage 50: 56-66.

7. Baxter CR (1994) Immunologic reactions in chronic wounds. Am J Surg 167: $12 \mathrm{~S}-14 \mathrm{~S}$.

8. Falanga V (1992) Growth factors and chronic wounds: the need to understand the microenvironment. J Dermatol 19: 667-672. 
Citation: Chen X, Li Y, Liang X, Wang Y, Wang MS, et al. (2020) Combining Negative Pressure Wound Therapy with Insulin Instillation Reduces Insulin Resistance and Accelerates Healing in Patients with Chronically Infected Wounds. J Emerg Med Trauma Surg Care 7: 057.

9. Grewal RS, Gupta SC, Singhal GM (1972) Wound healing in relation to insulin. Int Surg 57: 229-232.

10. Rosenthal SP (1968) Acceleration of primary wound healing by insulin. Arch Surg 96: 53-55.

11. Pierre EJ, Barrow RE, Hawkins HK, Nguyen TT, Sakurai Y, et al. (1998) Effects of insulin on wound healing. J Trauma 44: 342-345.

12. Hanam SR, Singleton CE, Rudek W (1983) The effect of topical insulin on infected cutaneous ulcerations in diabetic and nondiabetic mice. J Foot Surg 22: 298-301.

13. Greenway SE, Filler LE, Greenway FL (1999) Topical insulin in wound healing: a randomised, double-blind, placebo-controlled trial. J Wound Care 8: 526-528.

14. Lopez JE, Mena B (1968) Local insulin for diabetic gangrene. Lancet 1: 1199.

15. Wilson JM, Baines R, Babu ED, Kelley CJ (2008) A role for topical insulin in the management problematic surgical wounds. Ann R Coll Surg Engl 90: 160 .

16. Foltynski P (2018) Ways to increase precision and accuracy of wound area measurement using smart devices: Advanced app Planimator. PLoS One 13: e0192485.

17. Matthews DR, Hosker JP, Rudenski AS, Naylor BA, Treacher DF, et al (1985) Homeostasis model assessment: insulin resistance and beta-cell function from fasting serum glucose and insulin concentrations in man. Diabetologia 28: 412-419.

18. Katz A, Nambi SS, Mather K, Baron AD, Follmann DA, et al. (2000) Quantitative insulin sensitivity check index: a simple, accurate method for assessing insulin sensitivity in humans. J Clin Endocrinol Metab 85: 2402-2410.

19. McAuley KA, Mann JI, Chase JG, Lotz TF, Shaw GM (2007) Point: HOMA--satisfactory for the time being: HOMA: the best bet for the simple determination of insulin sensitivity, until something better comes along. Diabetes Care 30: 2411-2413.

20. Borai A, Livingstone C, Kaddam IB, Ferns G (2011) Selection of the appropriate method for the assessment of insulin resistance. BMC Med Res Methodol 11: 158

21. Serra R, Rizzuto A, Rossi A, Perri P, Barbetta A, et al. (2017) Skin grafting for the treatment of chronic leg ulcers - a systematic review in evidencebased medicine. Int Wound J 14: 149-157.

22. Desman E, Bartow W, Anderson LH (2015) Human Skin Allograft for Patients with Diabetic Foot Ulcers, Venous Leg Ulcers, or Surgical/ Traumatic Wounds Retrospective, Descriptive Study. Ostomy Wound Manage 61: 16-22.

23. Tanaka T, Panthee N, Itoda Y, Yamauchi N, Fukayama M, et al. (2016) Negative pressure wound therapy induces early wound healing by increased and accelerated expression of vascular endothelial growth factor receptors. Eur J Plast Surg 39: 247-256.

24. Rupert P, Ochoa RA, Punch L, Epps JV, Gordon-Burroughs S, et al. (2016) The Use of NPWT-i Technology, in Complex Surgical Wounds. Cureus 8: e920.

25. Yang Liu, Qin Zhou, Yunchuan Wang (2014) Negative Pressure Wound Therapy Decreases Mortality in a Murine Model of Burn-Wound Sepsis Involving Pseudomonas aeruginosa Infection. PLoS One 9: e90494.
26. Cheng HT, Hsu YC, Wu CI (2014) Efficacy and safety of negative pressure wound therapy for Szilagyi grade III peripheral vascular graft infection. Interact Cardiovasc Thorac Surg 19: 1048-1052.

27. Suh H, Lee AY, Park EJ, Hong JP (2016) Negative pressure wound therapy on closed surgical wounds with dead space: Animal study using a swine model. Ann Plast Surg 76: 717-722.

28. Watters C, Everett JA, Haley C, Clinton A, Rumbaugh KP (2014) Insulin treatment modulates the host immune system to enhance pseudomonas aeruginosa wound biofilms. Infect Immun 82: 92-100.

29. Scimeca CL, Bharara M, Fisher TK, Kimbriel H, Mills JL, et al. (2010) Novel Use of Insulin in Continuous-Instillation Negative Pressure Wound Therapy as "Wound Chemotherapy". J Diabetes Sci Technol 4: 820-824.

30. Nasole E, Nicoletti C, Yang ZJ, Girelli A, Rubini A, et al. (2014) Effects of alpha lipoic acid and its $\mathrm{R}+$ enantiomer supplemented to hyperbaric oxygen therapy on interleukin-6, TNF- $\alpha$ and EGF production in chronic leg wound healing. J Enzyme Inhib Med Chem 29: 297-302.

31. Li G, Barrett EJ, Barrett MO, Cao W, Liu Z (2007) Tumor necrosis factor-alpha induces insulin resistance in endothelial cells via a p38 mitogen-activated protein kinase-dependent pathway. Endocrinology 148 3356-3363.

32. Dandona P, Aljada A, Bandyopadhyay A (2004) Inflammation: the link between insulin resistance, obesity and diabetes. Trends in immunology 25: 4-7.

33. Klover PJ, Clementi AH, Mooney RA (2005) Interleukin-6 depletion selectively improves hepatic insulin action in obesity. Endocrinology 146 3417-3427.

34. Klover PJ, Zimmers TA, Koniaris LG, Mooney RA (2003) Chronic exposure to interleukin-6 causes hepatic insulin resistance in mice. Diabetes 52: 2784-2789.

35. O’Doherty R, Stein D, Foley J (1997) Insulin resistance. Diabetologia 3: B10-B15.

36. Feve B, Bastard JP (2009) The role of interleukins in insulin resistance and type 2 diabetes mellitus. Nat Rev Endocrinol 5: 305-311.

37. Hotamisligil GS (2003) Inflammatory pathways and insulin action. Int J Obes Relat Metab Disord 27: S53-S55.

38. Moller DE (2000) Potential role of TNF-alpha in the pathogenesis of insulin resistance and type 2 diabetes. Trends Endocrinol Metab 11: 212-217.

39. Yang P, Pei Q, Yu T, Chang Q, Wang D, et al. (2016) Compromised wound healing in ischemic type 2 diabetic rats. PLoS One 11: e0152068.

40. Choi K, Kim YB (2010) Molecular mechanism of insulin resistance in obesity and type 2 diabetes. Korean J Intern Med 25: 119-129.

41. Brem H, Tomic-Canic M (2007) Cellular and molecular basis of wound healing in diabetes. J Clin Invest 117: 1219-1222.

42. Brownlee M (2001) Biochemistry and molecular cell biology of diabetic complications. Nature 414: 813-820.

43. Geffner ME, Golde DW (1988) Selective insulin action on skin, ovary, and heart in insulin-resistant states. Diabetes Care 11: 500-505. 


\section{H}

Advances In Industrial Biotechnology | ISSN: 2639-5665

Advances In Microbiology Research | ISSN: 2689-694X

Archives Of Surgery And Surgical Education | ISSN: 2689-3126

Archives Of Urology

Archives Of Zoological Studies | ISSN: 2640-7779

Current Trends Medical And Biological Engineering

International Journal Of Case Reports And Therapeutic Studies | ISSN: 2689-310X

Journal Of Addiction \& Addictive Disorders | ISSN: 2578-7276

Journal Of Agronomy \& Agricultural Science | ISSN: 2689-8292

Journal Of AIDS Clinical Research \& STDs | ISSN: 2572-7370

Journal Of Alcoholism Drug Abuse \& Substance Dependence | ISSN: 2572-9594

Journal Of Allergy Disorders \& Therapy | ISSN: 2470-749X

Journal Of Alternative Complementary \& Integrative Medicine | ISSN: 2470-7562

Journal Of Alzheimers \& Neurodegenerative Diseases | ISSN: 2572-9608

Journal Of Anesthesia \& Clinical Care | ISSN: 2378-8879

Journal Of Angiology \& Vascular Surgery | ISSN: 2572-7397

Journal Of Animal Research \& Veterinary Science | ISSN: 2639-375

Journal Of Aquaculture \& Fisheries | ISSN: 2576-5523

Journal Of Atmospheric \& Earth Sciences | ISSN: 2689-8780

Journal Of Biotech Research \& Biochemistry

Journal Of Brain \& Neuroscience Research

Journal Of Cancer Biology \& Treatment | ISSN: 2470-7546

Journal Of Cardiology Study \& Research | ISSN: 2640-768X

Journal Of Cell Biology \& Cell Metabolism | ISSN: 2381-1943

Journal Of Clinical Dermatology \& Therapy | ISSN: 2378-8771

Journal Of Clinical Immunology \& Immunotherapy | ISSN: 2378-8844

Journal Of Clinical Studies \& Medical Case Reports | ISSN: 2378-880

Journal Of Community Medicine \& Public Health Care | ISSN: 2381-1978

Journal Of Cytology \& Tissue Biology | ISSN: 2378-9107

Journal Of Dairy Research \& Technology | ISSN: 2688-9315

Journal Of Dentistry Oral Health \& Cosmesis | ISSN: 2473-6783

Journal Of Diabetes \& Metabolic Disorders | ISSN: 2381-201X

Journal Of Emergency Medicine Trauma \& Surgical Care | ISSN: 2378-8798

Journal Of Environmental Science Current Research | ISSN: 2643-5020

Journal Of Food Science \& Nutrition | ISSN: 2470-1076

Journal Of Forensic Legal \& Investigative Sciences | ISSN: 2473-733X

Journal Of Gastroenterology \& Hepatology Research | ISSN: 2574-2566
Journal Of Genetics \& Genomic Sciences | ISSN: 2574-2485

Journal Of Gerontology \& Geriatric Medicine | ISSN: 2381-8662

Journal Of Hematology Blood Transfusion \& Disorders | ISSN: 2572-2999

Journal Of Hospice \& Palliative Medical Care

Journal Of Human Endocrinology | ISSN: 2572-9640

Journal Of Infectious \& Non Infectious Diseases | ISSN: 2381-8654

Journal Of Internal Medicine \& Primary Healthcare | ISSN: 2574-2493

Journal Of Light \& Laser Current Trends

Journal Of Medicine Study \& Research | ISSN: 2639-5657

Journal Of Modern Chemical Sciences

Journal Of Nanotechnology Nanomedicine \& Nanobiotechnology | ISSN: 2381-2044

Journal Of Neonatology \& Clinical Pediatrics | ISSN: 2378-878X

Journal Of Nephrology \& Renal Therapy | ISSN: 2473-7313

Journal Of Non Invasive Vascular Investigation | ISSN: 2572-7400

Journal Of Nuclear Medicine Radiology \& Radiation Therapy | ISSN: 2572-7419

Journal Of Obesity \& Weight Loss | ISSN: 2473-7372

Journal Of Ophthalmology \& Clinical Research | ISSN: 2378-8887

Journal Of Orthopedic Research \& Physiotherapy | ISSN: 2381-2052

Journal Of Otolaryngology Head \& Neck Surgery | ISSN: 2573-010X

Journal Of Pathology Clinical \& Medical Research

Journal Of Pharmacology Pharmaceutics \& Pharmacovigilance | ISSN: 2639-5649

Journal Of Physical Medicine Rehabilitation \& Disabilities | ISSN: 2381-8670

Journal Of Plant Science Current Research | ISSN: 2639-3743

Journal Of Practical \& Professional Nursing | ISSN: 2639-568

Journal Of Protein Research \& Bioinformatics

Journal Of Psychiatry Depression \& Anxiety | ISSN: 2573-0150

Journal Of Pulmonary Medicine \& Respiratory Research | ISSN: 2573-0177

Journal Of Reproductive Medicine Gynaecology \& Obstetrics | ISSN: 2574-2574

Journal Of Stem Cells Research Development \& Therapy | ISSN: 2381-2060

Journal Of Surgery Current Trends \& Innovations | ISSN: 2578-7284

Journal Of Toxicology Current Research | ISSN: 2639-3735

Journal Of Translational Science And Research

Journal Of Vaccines Research \& Vaccination | ISSN: 2573-0193

Journal Of Virology \& Antivirals

Sports Medicine And Injury Care Journal | ISSN: 2689-8829

Trends In Anatomy \& Physiology | ISSN: 2640-7752

Submit Your Manuscript: https://www.heraldopenaccess.us/submit-manuscript 